\title{
LIMITED-LIABILITY CONTRACTS WITH EARNINGS MANAGEMENT
}

\author{
Joshua Ronen \\ Department of Accounting, Taxation, and Business Law \\ Stern School of Business \\ New York University \\ 310 Tisch-Hall \\ NYC 10012-1118 \\ E-mail jronen@ stern.nyu.edu \\ Varda (Lewinstein) Yaari \\ Department of Business administration \\ School of Management \\ Ben-Gurion University \\ Beer-Sheba, Israel \\ E-mail: yvarda@bgumail.bgu.ac.il
}

November 2000

\begin{abstract}
Acknowledgements: We are grateful to the participants of the First World Congress of the Game Theory Society, Bilbao Spain, July 2000, where we presented our project: Renegotiation-Proof Principal-Agent Contracts with Unobservable Outcome. The first author acknowledges the hospitability of the London Business School during the final stages of preparation of this manuscript, and the second author acknowledges the hospitability of Baruch College and the Department of Accountancy's Chairman, Steve Lilien. While we be nefited from valuable discussions with our colleagues, the responsibility of any remaining mistakes is solely ours.
\end{abstract}

This paper can be downloaded from the Social Science Research Network Electronic Paper Collection: http://papers.ssrn.com/paper.taf?abstract_id=255274 


\title{
LIMITED-LIABILITY CONTRACTS WITH EARNINGS MANAGEMENT
}

\begin{abstract}
Numerous principal-agent situations of interest to accounting involve limited liability by the agent. We explore this issue when the outcome is mutually observable (MOC) and when it is not and the contract is based instead on the agent's report (NCC). We find that when outcome is not observable, the effect of limited lia bility depends on the level of limited liability: when low no effect; when medium - the principal fine-tunes payments based on a post-outcome imperfect public signal to compensate for the loss in flexibility caused by the agent's limited liability; when high - the agent's expected utility exceeds his reservation utility level and the public signal's use is limited. Next, we invoke the revelation principle and examine an incentive-compatible contract (RPC). Interestingly, RPC coincides with MOC when the limited liability is low and resembles NCC when limited liability is either medium or high. In addition, the impact of limited liability on the demand for earnings management is examined.
\end{abstract}

Key words: Limited liability, principalagent game, report ma nipulation, unobservable -outcome contract, earnings management. 
For a truly positive theory of contracts, a more reasonable assumption is that buyers and sellers operate in an environment of limited liability (Demougin and Garvie, 1991, p. 478).

\section{INTRODUCTION}

Many problems in accounting have been studied as principalagent ${ }^{1}$ contracts. $^{2}$ Surprisingly, while limited liability is an indispensable feature of principalagent contracts between creditors and shareholders, between managers and stakeholders, and between employers and workers, negligible attention has been given to the effect of limited liability on the shape, and the resulting payoffs, of the principal-agent contracts. ${ }^{3}$

In this study, we characterize the effect of the agent's limited liability on the equilibrium one-shot principałagent contracts. ${ }^{4}$ We distinguish between two types of settings: In the first, both principal and agent observe the outcome, so that the outcome can be incorporated into the contract's base. This contract characterizes, as an example, the situation in which the agent is a cost/revenue or profit center, and all costs/revenues are traceable to the agent. In what follows, we refer to the contract based on a mutually observable outcome as MOC.

\footnotetext{
${ }^{1}$ Since o utcome depends on both effort and chance, the principal cannot perfectly infer the agent's efforts. A given level of effort gives rise to a probability distribution of outcomes. The standard assumption is that higher effort increases the likelihood of higher outcome in a first-order-stochastic dominance sense (see, e.g., Holmstrom (1979)).

${ }^{2}$ See, e.g., Baiman and Demski (1980a) on the design of control systems; Baiman and Evans (1983) on the value of communication of pre-decision signal; Kim and Suh (1991) on the design of accounting information systems; Evans and Sridhar (1996) on the internal demand for earnings management; Baiman, Evans, and Noel (1987) on the optimal contracting with an auditor; Demski and Sappington (1993) on outsourcing; Christensen and Feltham (1997, 1999) on the value of communication and the design of performance measures; and Baiman and Rajan (1998) on optimal cost targets.

${ }^{3}$ One possible explanation is due to Mirrlees (1974). When the agent's utility is unbounded from below, as in the log family utility functions, the principal can threaten him with an extremely harsh penalty upon observing a low outcome to induce him to exert first-best effort. Limited liability bounds the agent's utility from below. Hence, limited liability that prevents extremely harsh penalties, but does not affect payments of the second-best contract, is assumed implicitly by any study that characterizes the second-best equilibrium. In this regard, our work extends the research into limited liability ranging from minus infinity to an arbitrarily large positive level.

${ }^{4}$ Liability of minus infinity captures the special case in which the agent does not have limited liability.
} 
In the second setting, we relax the assumption that outcome is observable and replace it with a weaker assumption that the agent alone observes the outcome and the contract is based, instead, on an imperfectly audited report. The agent therefore can "manage" the report with some success. This is the case, for example, for firms whose managers (the agents) release public reports to shareholders (the principals). There is ample evidence that managers receive bonuses based on the accounting numbers (see e.g., Healy (1985)) and that firms "manage earnings" (see, e.g., Ronen and Sadan (1981) and the recent survey by Healy and Wahlen (1999))). In this setting, we distinguish between two contracts: in the first, the communication channels between the principal and the agent are blocked after the contract's design stage (NCC) ${ }^{5}$; in the second, communication is not barred. When the principal and the agent can communicate after the agent learns the actual outcome, there are many possible mechanisms. For example, the principal and agent can renegotiate the contract, or the agent could send a message to the principal only when the news is bad, etc. To resolve this multiplicity of contracting options, we invoke the revelation principle, which states that there is no loss of generality in restricting analysis to a direct truthful mechanism (i.e., the principal designs a contract that induces the agent to send him truthful messages). That is, the principal designs a revelation contract (RPC). Note that because the NCC emerges when information channels are prohibitively costly, unlike RPC, the revelation principle cannot be invoked to characterize the payoffs of the principal and agent in NCC.

We solve for the three contracts: MOC, NCC, and RPC. The main findings are: (1) In MOC there is a thre shold liability level, $L^{*}$, such that all agents with higher limited liability enjoy a rent (i.e., the agent's expected utility exceeds his reservation utility level); we show that the more difficult it is to induce the agent to exert effort, the higher the rent. (2) When outcome is not observed by the principal, then, only when limited liability does not exceed a critical maximum

\footnotetext{
5 This assumption is prevalent in the earnings management literature (see Evans and Sridhar(1996), Arya, Glover, and Sunder (1998), and the discussion in Christensen and Feltham (1998)).
} 
threshold, $\mathrm{L}^{*}$, (and only then) the cost to the less-informed principal of earnings management can be completely avoided through the design of a contract that invokes the revelation principle. That is, the payoffs of MOC coincide with the payoffs of RPC when limited liability is sufficiently low. The only difference between the two contracts lies in the role of an imperfectly audited report of outcome: It is redundant in MOC but it is essential in RPC to induce the agent to tell the truth; (3) When limited liability exceeds this critical maximum threshold, the structure of the revelation contract (RPC) changes, and now resembles that of NCC. Specifically, both contracts will include a post-outcome imperfect public signal as an argument in the compensation function, and some of the payments will coincide. The principal fine-tunes payments based on the postoutcome signal to compensate for the loss in flexibility caused by the agent's limited liability. For some limited-liability levels (that exceed $\mathrm{L}^{*}$ ), the principal thus pushes the agent closer to his reservation utility level.

Earnings management is a mainstream issue in accounting; Levitt (1998), for example, expressed alarm at the practice of earnings management, because it reduces the quality of the accounting reports with adverse consequences for the strength and the success of the U.S. capital markets. (See also Dechow and Skinner (2000)). Our analysis contributes insights to that part of the earnings management literature concerned with the internal demand for earnings management; i.e., the contracting value of earnings management in the context of the principalagent relationship (see e.g., Evans and Sridhar (1996)). Because the revelation principle allows researchers to restrict attention to truth-telling equilibria, studies of earnings management have made assumptions that violate this principle. In a one-shot game, where the principal's commitment not to use the agent's revelations against him is not an issue, two such violations are commonly assumed. 
The first is barred communication (see, e.g., Demski (1988) and Newman (1998)). Our analysis here demonstrates, however, that limited liability can induce earnings-management payoffs even when the communication between principal and agent after the outcome is realized is not barred.

Arya, Glover, and Sunder (1998) note that a second violation involves restrictions on the shape of the contract. In Healy (1985), for example, the contract is capped from above and from below. In repeated relationships, such contracts induce managers to manage earnings by "taking a bath." A plausible reason from a contract to be capped from be low is the manager's limited liability. In this regard, our study is an exploration of the extent to which limited liability constitutes a constraint on the shape of optimal one-shot contracts that gives rise to an internal demand for earnings management. ${ }^{6}$

To the best of our knowledge, Sappington (1983) first analyzed the effect of the agent's limited liability on the principalagent contract. As is well known, when a principal contracts with a risk-neutral agent with unlimited wealth, a first-best contract is feasible by selling the enterprise to the agent, thus imposing all risk on the agent [Harris and Raviv (1979)]. Sappington shows that the first-best contract is no longer feasible when the agent has limited liability. This result was exploited by Antle and Eppen (1985), Fellingham and Young (1990), Arya, Glover, and Sivaramakrishnan (1997)) and others to derive insights into accounting issues, modeling the problem as a second-best principalagent game with a risk-neutral agent, whose limited liability protects him from bankruptcy.

Innes (1990), Park (1995), and Kim (1997) have analyzed similar situations. Innes finds that a debt contract is optimal when both principal and agent have limited liability. Park and Kim

\footnotetext{
${ }^{6}$ For instance, a penalty contract can induce truthful full disclosure at no cost to the principal. In contrast to Penno (1987), who specifies such penalty as would generate negative infinite utility for the agent, we show that milder penalties, which might even amount to a small positive transfer from the principal to the agent (generating positive utility for the agent), can achieve a truthful equilibrium.
} 
find that a bonus contract can achieve the first-best under some conditions on technology. They explain the apparent inconsistency with Sappington's study as a matter of assumptions: Sappington assumes that the agent exerts effort after he observes a productivity-related signal, while they place the exertion before the observation. Basu (1992) and Sengupta (1997) derive similar results in a somewhat different setting: Basu studies moral hazard in the choice of technologies, and Sengupta extends this model by studying moral hazard in both technology choice and effort. Pitchford (1998) studies a similar framework, allowing the bargaining power to vary with the agent's limited liability (in contrast to the standard model, which assumes that all the bargaining power lies with the principal). He finds that a first-best scheme becomes attainable only when all the bargaining power lies in the hands of the agent. The intuition of this result is that in this case the agent bears all the risk, as required by Harris and Raviv's scheme. Demski, Sappington, and Spiller (1988) extend the multiagent model of Demski and Sappington (1984) to an environment in which the agents have limited liability on the level of payments. They find that the first-best solution is more likely to be feasible if the limited liability is small relative to the agents' reservation utility. ${ }^{7}$

7

7 Additional papers study the effect of limited liability on the contract when the principal faces an agent of unknown type [Lawarrée and Van Audenrode $(1992,1996)$ and Demougin and Garvie (1991)]. Lawarrée and Van Audenrode (1992) analyze the effect of the agent's limited liability on the principal's ability to extract a first-best allocation from an agent of unknown type by stochastic auditing. They find that limited liability renders auditing too costly, because the penalty for misrepresentation (triggered by the audit) must be balanced by a transfer to the agent to keep the latter at his limited liability's level.

Lawarrée and Van Audenrode (1996) study a model with an unobservable outcome. They find that, because the principal and the ag ent are risk-neutral, the unobservability of the outcome is not an obstacle in itself to achieving a first-best outcome, unless the agent is also protected by limited liability. In the latter case, the high-productivity agent exerts less than the first-be st level, and both high-and low-productivity agents earn rent. Their results depend crucially on the imperfection of the 'lie detector type' monitoring technology. In particular, because the principal cannot distinguish between a high-productivity agent shirking and a high-productivity agent mistakenly accused of shirking, he has an incentive to reduce the effort of the high-productivity agent.

Demougin and Garvie (1991) analyze the effect of limited liability on the principal-agent contract when the riskneutral principal contracts with a risk-neutral agent of unknown type and he can use an ex-post signal correlated with the agent's private information in contracting. They study a few scenarios, characterizing for each the optimal mechanism design, which turns out to have a unique shape, regardless of the level of limited liability. They offer a number of interesting insights. Previous studies report the puzzling finding that the contract's efficiency is independent of the quality of the ex-post signal. Demougin and Garvie show that when the agents' payments are protected by limited liability welfare and production increase in the information content of the signal. They also 
Our paper is different from these papers in that we analyze a second-best scenario because the agent is risk-averse. Hence, we find that the difficulty of inducing the agent to exert effort exacerbates the effect of the agent's limited liability on the costliness of the contract, while the above studies are concerned with the feasibility of a first-best allocation. Second, in contrast to the literature that assumes that limited liability renders some payments infeasible, we give full characterization of how the contracts vary along the range of limited liability. Third, we offer a comparison of contracts that are different in the information available for contracting across a given level of limited liability: in MOC the outcome is observable, in NCC it is not, and in RPC it can be elicited from the agent at some nonnegative cost.

The paper proceeds as follows. Section 2 presents the model. Section 3 analyzes MOC. Sections 4 and 5 analyze NCC and RPC, respectively. Section 6 summarizes our findings and offers our conclusions.

\section{THE MODEL}

The game includes a risk-neutral principal and a risk-averse, work-averse agent, with limited liability, $\mathrm{L}, \mathrm{L} \in(-\infty, \hat{\mathrm{L}}]$. The agent exerts unobservable effort, $a, a \in\left\{a_{1}, a_{2}\right\}$, where $a_{1}<a_{2}$. Jointly with nature, the agent's effort determines the unobservable outcome, $x$, which is either bad, B, or good, G; i.e., $x \in\{\mathrm{B}, \mathrm{G}\}, \mathrm{B}<\mathrm{G}$. The probability of $x=\mathrm{G}$ when effort is $a_{\mathrm{j}}$ is denoted by $\grave{\mathrm{e}}_{\mathrm{j}}$. As is standard in principalagent games, we assume that that $\grave{\mathrm{e}}_{1}<\grave{\mathrm{e}}_{2}$ : the higher the agent's effort, the higher the expected outcome.

\footnotetext{
characterize the case in which limited liability takes the form of protect ion of the agent's profits (salary minus cost of effort), finding that first-best solutions that are feasible when limited liability covered payments only is no longer feasible, and that the information rent of the agent increases in the private cost of exerting effort. The main difference between this study and ours, apart from the fact that in our model the principal knows the agent's type, is that we find that limited liability affects the contract's formula. It limits the principal's ability to use information variables to alleviate the report-management problem in NCC; it limits the principal's ability to threaten the agent with an appropriate penalty in RPC.
} 
The agent does not report outcome directly to the principal. Instead, after he learns the actual outcome, the agent submits a preliminary report to a third party - an imperfect monitor (such as an auditor), who examines it and prepares a report, $r, r \in\{\mathrm{B}, \mathrm{G}\}$, for the principal. The agent's strategy, $d$, is either to communicate the truth, $\mathrm{T}$, or to misrepresent, $\mathrm{T}^{\mathrm{c}}, d: x \rightarrow\left\{\mathrm{T}, \mathrm{T}^{\mathrm{c}}\right\} \subseteq$ $\{B, G\}$. The audit technology has a one-sided error. If the agent chooses truth-telling, the report is truthful for sure, $1=\operatorname{Pr}(r=x \mid \mathrm{T})$, and if he does not, the monitor discovers the truth with some positive probability, $\pi, \pi=\operatorname{Pr}\left(r=x \mid \mathrm{T}^{\mathrm{c}}\right)$, where $1 / 2<\pi<1$. $^{8}$

The time-line of main events is as follows:

Date 1: The principal hires an agent with limited liability L and designs his contract.

Date 2: The agent chooses effort, $a$.

Date 3: The outcome, $x$, is realized and observed by the agent alone.

Date 4: The principal and agent can contract again, either directly or indirectly.

Date 5: - The agent communicates the outcome to an independent monitor, who issues a public report, $r$.

- A public signal, $s$, imperfectly correlated with the outcome, is now available, $s$, $s \in\{\ell, h\}, \ell$ for low and $h$ for high. In particular, $\operatorname{Pr}(s=h \mid x=\mathrm{G})=\operatorname{Pr}(s=\ell \mid x=\mathrm{B})=\rho>1 / 2$ $\operatorname{Pr}(s=h \mid x=\mathrm{B})=\operatorname{Pr}(s=\ell \mid x=\mathrm{G})=1-\rho$.

Date 6: The agent is paid and quits.

$\bullet$

Date 7: The principal collects the residual outcome (outcome less payment to the agent).

\footnotetext{
${ }^{8}$ Such an audit technology is typical in monitoring systems that look for exceptions and unusual findings. It is, for example, representative of the audit technology of independent auditors. For a valuable discussion of this point, consult Schwartz (1997).
} 
Note that the principal learns the actual outcome long after the agent has left, so he cannot use this knowledge to induce the agent to report truthfully.

The principal maximizes the expected residual outcome. The agent has a utility function that is separable in monetary income, $\mathrm{W}($.$) , and effort, -\mathrm{V}(a)$, where $\mathrm{W}$ is a von NeumannMorgenstern utility function with $\mathrm{W}^{\prime}>0$ and $\mathrm{W}^{\prime \prime}<0$, and the disutility of the agent over effort is an increasing, strictly convex function, $\mathrm{V}^{\prime}>0$ and $\mathrm{V}^{\prime \prime}>0$. The agent can obtain expected utility of Wo in an alternative job. The agent enjoys limited liability in that no payment in the contract can be lower than a threshold level, L. $\mathrm{L} \rightarrow-\infty$ captures the special case in which the agent does not have limited liability.

We assume that the principal wants to motivate the agent to exert the higher level of effort; that is, the cost of inducing the agent to exert greater effort is lower than the resulting increase in the expected outcome, $\left[\grave{e}_{2}-\grave{\mathrm{e}}_{1}\right][\mathrm{G}-\mathrm{B}]$.

We find the equilibrium contracts by solving the principal's program when he designs the contract with the agent. We look for efficient contracts that maximize the principal's expected payoff subject to the following constraints:

- The agent is willing to contract because the contract guarantees him at least his reservation utility, Wo. That is, EW(.) $-a_{2} \geq$ Wo. ${ }^{9}$

- The agent is induced to choose the higher level of effort.

That is, $\mathrm{E}\left(\mathrm{W}\left(. \mid a_{2}\right)\right)-\mathrm{V}\left(a_{2}\right) \geq \mathrm{E}\left(\mathrm{W}\left(. \mid a_{1}\right)\right)-\mathrm{V}\left(a_{1}\right)$.

- The limited liability of the agent is satisfied. That is, for each payment $\mathrm{Z}$,

$$
\mathrm{W}(\mathrm{Z}) \geq \mathrm{W}(\mathrm{L})
$$

\footnotetext{
${ }^{9}$ Similar to the literature, we assume that the reservation utility of the agent does not vary with his limited liability. Such an assumption makes the comparison among different limited-liability contracts meaningful.
} 
In what follows, for parsimony, we will use the same notation for the Lagrange multipliers of these constraints in our three different programs. Specifically, $\lambda, \mu$, and $\varphi$ are the Lagrange multipliers of (PC), (MH), and (LL), respectively .

\section{THE MUTUALLY OBSERVABLE OUTCOME CONTRACT (MOC)}

In this section, we analyze the contract when the outcome is mutually observable, $M$, $M: x \times s \rightarrow \mathrm{R}$, henceforth referred to as MOC (Mutually Observable Outcome Contract).

The principal has two pieces of data available for contracting: the outcome, $x$, and the post-decision signal, $s$. Since the latter is a noisy signal of the outcome, by Holmstrom's (1979) informativeness principle, it is redundant for contracting. The principal then solves the following M-program:

(M) $\quad \operatorname{Max} \mathrm{E}_{x}\left(x-M_{x} \mid a_{2}\right)$ $M(x)$

s.t.

(PC), (MH), and (LL) obtain.

The solution of this contract is characterized in the following lemma.

\section{LEMMA 1:}

Designate a critical limited-liability level, $\mathrm{L}^{*}=\mathrm{W}_{\mathrm{o}}+\mathrm{V}\left(a_{2}\right)-\theta_{2} v$. In equilibrium,

(a) If $\mathrm{L}<\mathrm{L}^{*}$, MOC is characterized by two payment levels, $M_{\mathrm{G}}$ and $M_{\mathrm{B}}$ :

$$
\begin{aligned}
& M_{\mathrm{G}}=\mathrm{W}^{-1}(\mathrm{~W}(M(\mathrm{~B}))+v), \\
& M_{\mathrm{B}}=\mathrm{W}^{-1}\left(\mathrm{~W}_{\mathrm{o}}+\mathrm{V}\left(a_{2}\right)-\theta_{2} v\right)<M_{\mathrm{G}},
\end{aligned}
$$


where $v=\frac{\mathrm{V}\left(a_{2}\right)-\mathrm{V}\left(a_{1}\right)}{\grave{\mathrm{e}}_{2}-\grave{\mathrm{e}}_{1}}$.

(b) If $\mathrm{L} \geq \mathrm{L}^{*}, \mathrm{MOC}$ is characterized by two payment levels, $M_{\mathrm{G}}$ and $M_{\mathrm{B}}$ :

$$
\begin{aligned}
& \left.M_{\mathrm{G}}=\mathrm{W}^{-1}(\mathrm{~W}(\mathrm{~L}))+v\right), \\
& M_{\mathrm{B}}=\mathrm{L}<M_{\mathrm{G}} .
\end{aligned}
$$

The unlimited-liability contract is a well-known result (e.g., Ma (1991)). ${ }^{10}$ In the limitedliability contract the lowest payment, $M_{\mathrm{B}}$, must be set at the limited liability level, because the payment dictated by the first-order condition is rendered infeasible by the agent's limited liability. In both cases, the agent is paid more for $\mathrm{G}$ than for $\mathrm{B}$, to induce him to exert effort. ${ }^{11}$

The difference between payments for a good and a bad outcome, measured in utils, equals $v=\frac{\mathrm{V}\left(a_{2}\right)-\mathrm{V}\left(a_{1}\right)}{\grave{\mathrm{e}}_{2}-\grave{\mathrm{e}}_{1}}$. the higher $v$, the larger the gap between $\mathrm{M}_{\mathrm{G}}$ and $M_{\mathrm{B}}$, which implies that the contract is more risky and, hence, more costly to the principal (for a formal proof of this statement consult, e.g., Tzur and Yaari (1999)). In what follows, we treat $v$ as a measure of the difficulty in inducing the agent to exert high effort: the larger the gap in the agent's disutility from exerting high effort, $\mathrm{V}\left(a_{2}\right)-\mathrm{V}\left(a_{1}\right)$, and the lower the sensitivity of the outcome to the agent's effort, $\theta_{2}-\theta_{1},{ }^{12}$ the higher $v$ is.

\footnotetext{
${ }^{10}$ To see the result clearly, note that $(\mathrm{PC})$ can be written as: $\grave{e}_{2}[\mathrm{~W}(M(\mathrm{G}))-\mathrm{W}(M(\mathrm{~B}))]+\mathrm{W}(M(\mathrm{~B}))-\mathrm{V}\left(a_{2}\right)=\mathrm{Wo}$, and the $(\mathrm{MH})$ constraint, after rearranging, becomes: $\mathrm{W}(M(\mathrm{G}))-\mathrm{W}(M(\mathrm{~B}))=v$.

${ }^{11}$ Let $\mathrm{W}(\mathrm{z})=\mathrm{z}^{1 / 2}, \mathrm{~W}_{\mathrm{o}}=9.25, \mathrm{~V}\left(a_{2}\right)=0.75$ and $\mathrm{V}\left(a_{1}\right)=0, \grave{\mathrm{e}}_{2}=0.65, \grave{\mathrm{e}}_{1}=0.55$. Then, in the unlimited-liability contract, $M(\mathrm{G})=159.39, M(\mathrm{~B})=26.26$, and the expected contract's cost is 112.80 . More numerical examples are provided below.

12 The higher $\grave{e}_{2}-\grave{e ̀}_{1}$, the more attractive exerting effort is, since the likelihood of a good outcome ishigher (and the compensation is thus higher).
} 
Definition: The cost of limited liability, $\Delta$, is the increment in the cost of the contracts due to a binding (LL).

$\Delta$ is the difference in the contract's cost had the principal been able to offer the agent a contract as characterized in part (a) of Lemma 1, instead of the contract that he actually offers him because of the agent's limited liability, as characterized in part (b) of Lemma 1.

\section{PROPOSITION 1:}

When the principal observes the outcome and the limited liability of the agent affects the contract,

(a) then limited liability increases each payment, $M_{\mathrm{G}}$ and $M_{\mathrm{B}}$, and the agent's expected utility exceeds his reservation utility level.

(b) then the more difficult it is to motivate the agent to exert effort, the higher the cost of limited liability; i.e., $\Delta$, increases in $v$.

\section{Proof: See Appendix.}

Limited liability increases both $M_{\mathrm{G}}$ and $M_{\mathrm{B}}$ : the low payment, $M_{\mathrm{B}}$, is set at the limitedliability level, and the utility over the high payment, $\mathrm{W}\left(M_{\mathrm{G}}\right)$, exceeds the utility over the low payment, $\mathrm{W}\left(M_{\mathrm{B}}\right)$, by $v$ to provide the agent with incentives to exert effort. Furthermore, the more difficult it is to motivate the agent to exert effort (i.e., the higher $v$ ), the higher must be the good-outcome payment, $M_{\mathrm{G}}$, so limited liability is more costly. The intuition of this result lies in the agent's risk-aversion. Since his marginal utility is a decreasing function, the larger $v$, the larger the good-outcome payment, $M_{\mathrm{G}}$, that is required to guarantee the agent the required utility 
level, $\mathrm{W}\left(M_{\mathrm{G}}\right)$, for a given $\mathrm{L}$. Since limited liability increases the low payment, it exacerbates this effect.

\section{THE UNOBSERVABLE-OUTCOME CONTRACT WITH NO OPEN COMMUNICATION CHANNELS}

In this section and the following one, we assume that the principal does not observe the outcome. Since, in principle, contracts must be based on mutually observable variables, the outcome can no longer be a basis for the contract. Instead, the principal can use the audited report on the outcome, $r$, and the public signal, $s$.

\subsection{The no-communication contract (NCC)}

In this section, we assume that communication channels are prohibitively costly, and the principal and agent do not have any communication after the contract stage. We denote this contract by $C, C: r \times s \rightarrow \mathrm{R}$, henceforth referred to as NCC (No Communication Contract). The following lemma is useful for setting up the principal's C-program.

\section{LEMMA 2:}

(a) To motivate the agent to exert effort, his compensation for a good outcome is strictly higher than for a bad outcome.

(b) If a contract depends on the report nontrivially (i.e., different reports yield different compensation), the agent will manage the report by always presenting to the auditor a good outcome, G. That is, the agent's strategy is: 


$$
d(x)=\left\{\begin{array}{rrr}
T & \text { if } x=\mathrm{G} \\
T^{c} & \text { if } & x=\mathrm{B}
\end{array}\right\} .
$$

\section{Proof: See Appendix.}

Three circumstances give rise to "report management":

(1) The outcome is unobservable - necessitating reliance on the mutually observable report.

(2) Because of moral hazard, the agent's payoff varies with the reported outcome - inducing the utility-maximizing agent to misrepresent when the truth does not yield the maximum compensation.

(3) The outcome is imperfectly verifiable ex-post - precluding elicitation of the truth by the threat of penalties, triggered by stochastic auditing.

Townsend (1979), Evans (1980) ${ }^{13}$, Gale and Hellwig (1985), Baiman, Evans, and Noel (1987), Border and Sobel (1988), and others have investigated principalagent relationships with unobservable outcomes assuming a perfect, costly monitor employed stochastically. ${ }^{14} \mathrm{We}$, in contrast, assume a stochastic, costless, but imperfect monitor, which is a realistic assumption, for instance, for public companies. Audits of financial reports are mandatory in many countries at costs that are negligible relative to firms' values, but they rarely detect all misrepresentation.

The C-program that solves for NCC is:

\footnotetext{
13 In Evans (1980), the monitor detects faithfully both the true outcome and the unobservable effort of the agent. In our study, it detects outcome only.

14 Baiman and Demski (1980b) analyze a game where ou tcome is observable, but its decomposition into quantity and price variance is not. The principal has to decide whether to ex-post monitor the agent, costlessly, by acquiring information on these variances. They show that the principal is better off committing to the range of outcomes to trigger the variance analysis, rather than having the flexibility of making the decision after outcome is realized.
} 
(C) $\quad \operatorname{Max} \mathrm{E}_{x, s}\left(x-C_{r s} \mid a_{2}\right)$

$\left\{C_{r s}\right\}$

s.t.

(PC), (MH), and (LL) obtain.

This program yields the following first-order conditions:

$C_{G h}: \frac{1}{W^{\prime}\left(C_{G h}\right)}=\lambda+\frac{\grave{̀} Q}{\operatorname{Pr}(r=G, s=h)}$.

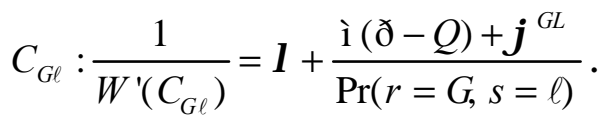

$C_{B}: \frac{1}{W^{\prime}\left(C_{B}\right)}=\lambda-\frac{\grave{\imath ̀}-\varphi^{B L}}{\operatorname{Pr}(r=\mathrm{B})}$,

where $Q=\rho-(1-\pi)(1-\rho)$ and $\pi-Q=1-\rho-(1-\pi) \rho$.

We proceed in a piecemeal fashion. The following proposition analyzes the equilibrium when limited liability does not affect the second-best contract.

\section{PROPOSITION 2:}

When limited liability does not affect the contract,

(a) the equilibrium NCC is a triplet, $\left\{C_{\mathrm{B}}, C_{G \ell}, C_{\mathrm{Gh}}\right\}$, where $C_{\mathrm{Gh}}>C_{G \ell}>C_{\mathrm{B}}$.

(b) NCC is more costly than MOC.

Proof: See Appendix.

The analysis of NCC indicates that, as in MOC, when $r=\mathrm{B}$, the report fully reveals the outcome and there thus is no need for the public signal. When $r=\mathrm{G}$, however, the public signal is 
needed to filter the noise in the imperfectly audited report. This result demonstrates that the less the principal knows, the more information variables are likely to be useful for contracting. ${ }^{15}$

The interesting issue here is how to interpret a combination of a good-outcome report with a low ex-post signal that indicates a bad outcome. The algebra shows that the answer depends on whether $\pi-Q$ is positive or negative. This translates to the condition of existence of a critical

level of $\rho$ relative to $\pi, \hat{n}=\frac{1}{2-ð}>1 / 2$ such that when $\rho$ is lower the report is more credible than the ex-post signal and hence the agent is paid more than the optimal risk-sharing arrangement (indicated by $\lambda$ ). When $\rho$ is higher, the public signal receives more weight and the report is less believed. The agent is then paid less than the optimal risk-sharing arrangement to deter him from not exerting high effort.

Previous papers have analyzed NCC (see, e.g., Evans and Sridhar's (1996)). The incorporation of the potentially false report in the principalagent contract is interpreted as establishing an internal demand for 'earnings management.' These studies. however, do not examine the effect of the agent's limited liability on the contract. We explore this feature in the following proposition.

\section{PROPOSITION 3:}

There are two levels of limited liability, $\mathrm{L}^{\mathrm{C}^{*}}$ and $\mathrm{L}^{\mathrm{C}^{* *}}$, where $\mathrm{L}^{\mathrm{C}^{*}}<\mathrm{L}^{\mathrm{C}^{* *}}$, such that:

(a) when $\mathrm{L}^{\mathrm{C}^{*}}<\mathrm{L}^{\mathrm{C}^{* *}}$, the agent's limited liability does not affect the contract. The equilibrium contract is as characterized in Proposition 2. The agent's expected payments guarantee the agent his reservation utility, Wo.

(b) if $\mathrm{L}^{\mathrm{C}^{*}} \leq \mathrm{L} \leq \mathrm{L}^{\mathrm{C}^{* *}}$, limited liability determines only one payment, $C_{\mathrm{B}}$,

\footnotetext{
${ }^{15}$ Let the parameters be as in footnote 10 , and $\rho=0.8$ and $\pi=0.75$. Then, $C_{B}=10.766, C_{G \ell}=100$, and $C_{G h}=176.39$. The expected cost is: $117.64>112.80$.
} 


$$
\begin{aligned}
& C_{\mathrm{Gh}}=\mathrm{W}^{-1}\left(\frac{v}{Q}-\frac{\partial-Q}{Q} \mathrm{~W}\left(C_{G \mathrm{~L}}\right)+\frac{\partial}{Q} \mathrm{~W}(\mathrm{~L})\right)>C_{G \ell} \cdot \\
& C_{G \ell}=\mathrm{W}^{-1}\left(\frac{K}{\operatorname{Pr}(r=G, s=\ell) Q-\operatorname{Pr}(r=G, s=h)(ð-Q)}\right)>\mathrm{L} . \\
& C_{\mathrm{B}}=\mathrm{L}, \\
& \text { where } K=Q\left[\mathrm{Wo}+\mathrm{V}\left(a_{2}\right)-ð\left(1-\grave{\mathrm{e}}_{2}\right) \mathrm{W}(\mathrm{L})\right]-\operatorname{Pr}(r=G, s=h)[v+ð \mathrm{~W}(\mathrm{~L})] .
\end{aligned}
$$

The agent obtains an expected utility that equals his reservation utility, Wo, but limited liability increases the contract's cost to the principal.

(c) if $\mathrm{L}>\mathrm{L}^{\mathrm{C} * *}, C_{\mathrm{Gh}}=\mathrm{W}^{-1}\left(\mathrm{~W}(\mathrm{~L})+\frac{v}{Q}\right)>C_{G \ell}=C_{B}=\mathrm{L}$. The agent obtains an expected utility, $\mathrm{W}(\mathrm{L})+\operatorname{Pr}(r=\mathrm{G}, s=h) \frac{v}{Q}$, that exceeds his reservation utility, Wo, and the contract is more expensive than in (b).

Proof: See Appendix.

Proposition 3 indicates how limited liability modifies NCC. If L is sufficiently low, $\mathrm{L}<\mathrm{L}^{\mathrm{C}^{*}}$, limited liability has no effect (case (a)). This, however, changes when limited liability increases and determines the lowest payment, $\mathrm{C}_{\mathrm{B}}$. Now, the principal reduces $\mathrm{C}_{G \ell}$ in order to motivate the agent to exert effort, leaving the expected utility at his reservation utility level. Reducing $\mathrm{C}_{G \ell}$ is feasible as long as $\mathrm{C}_{G \ell}$ exceeds $\mathrm{L}$. As $\mathrm{L}$ increases, $\mathrm{L}>\mathrm{L}^{\mathrm{C} * *}$, however, both $\mathrm{C}_{\mathrm{B}}$ and $\mathrm{C}_{G \ell}$ are set at the limited-liability level and the ex-ante expected utility of the agent exceeds his reservation-utility level, Wo.

Note that in MOC, there are only two regions of limited liability, while in NCC, we identify three distinct regions. If the level of limited liability is low, below $\mathrm{L}^{\mathrm{C} *}$, the $\mathrm{NCC}$ is unchanged relative to the case of unlimited liability. This is also the case in MOC when $\mathrm{L}<\mathrm{L}^{*}$ 
Also, there exists a range of higher limited liability levels where, even though the contract is more costly to the principal, the principal pushes the agent to his reservation utility by fine-tuning the components of the contract so that the agent does not enjoy a rent. To compensate for the fact that limited liability increases the lowest payment, the principal reduces the next to lowest payment (until it coincides with the limited-liability level). This is made possible because the principal incorporates into the contract an imperfect, post-outcome signal to filter the noise in the report due to report management. This possibility, naturally, does not exist in the case of MOC. When limited liability is sufficiently high, to exhaust this option, say at $\mathrm{L}^{\mathrm{C} * *}$, the use of the public signal is restricted and the agent enjoys a rent; this parallels MOC when $\mathrm{L}>\mathrm{L}^{*}$.

\section{THE REVELATION CONTRACT}

In this section, we analyze the contract between the principal and the agent when (i) the outcome is observable only by the agent, and (ii) the principal and agent communicate after the agent observes the outcome and before the auditor issues a report. This situation characterizes, for example, the compensation decisions of CEOs. After an initial signing of a multi-period contract, each year the compensation committee of the Board of Directors determines that year's CEO's compensation.

Since there are multiple possible mechanisms (as discussed in the Introduction), we invoke the revelation principle, which states that without loss of generality we can restrict the analysis to a game in which the principal induces the agent to honestly disclose what he knows to the

principal; the message is denoted by $\hat{x}, \hat{x} \in\{\hat{\mathrm{B}}, \hat{\mathrm{G}}\}$. In what follows, we denote the contract by $S$, $S: \hat{x} \times r \times s \rightarrow \mathrm{R}$, and refer to it as RPC (Revelation Principle Contract).

The principal designs $S$ by solving the following S-program: 
(S) $\operatorname{Max} \mathrm{E}(x-S(\hat{x}, r, s))$

$S, a$

s.t.

(PC), (MH), and (LL) obtain.

If $x=\mathrm{G}, \operatorname{EW}(\mathrm{S}, a \mid \hat{x}=\hat{\mathrm{G}}) \geq \operatorname{EW}((\mathrm{S}, a \mid \hat{x}=\hat{\mathrm{B}})$.

(IC.G)

If $x=\mathrm{B}, \operatorname{EW}(\mathrm{S}, a \mid \hat{x}=\hat{\mathrm{B}}) \geq \operatorname{EW}((\mathrm{S}, a \mid \hat{x}=\hat{\mathrm{G}})$.

The new constraints are the incentive-compatibility constraints, (IC.G) and (IC.B), stating that the agent (weakly) prefers to communicate the outcome truthfully to the principal. By Lemma 2, (IC.G) is not binding, because, in order to motivate him to exert effort, the contract must pay the agent more for $\mathrm{G}$ than for $\mathrm{B}$.

When the agent observes B, however, he weighs the utility from achieving a B-based compensation against the expected payoff from misrepresentation:

$$
\mathrm{EW}(S \mid \hat{x}=\hat{\mathrm{B}}, x=\mathrm{B}) \geq(1-\pi)\left[(1-\rho) \mathrm{W}\left(S_{G h}\right)+\rho \mathrm{W}\left(S_{G \ell}\right)\right]+\pi \mathrm{W}(\mathrm{P}(\mathrm{B}) \mid r=\mathrm{B}) .
$$

On the left-hand side is the agent's payoff when he communicates the truth. On the righthand side is his expected payoff from misrepresentation. With probability of $1-\pi$, his misrepresentation will be successful and his payoff would be determined by the realized $s$, and with probability $\pi$ the auditor will discover the truth and the agent would pay a penalty amount (or receive a reduced payment), $\mathrm{P}(\mathrm{B})$.

We start with characterization of the contract when limited lia bility is not an issue. In this case, the principal can increase the penalty by as much as he wishes. There are an infinite number of such penalties that elicit the truth from the agent while (IC.B) is not binding, because: 
$\mathrm{P}(\mathrm{B})<\mathrm{W}^{-1}\left(\frac{\mathrm{W}\left(M_{B}\right)-(1 ð) \mathrm{W}\left(M_{G}\right.}{\text { ठ }}\right)$.

When (IC) are not binding, the S-program and M-program are identical. We therefore obtain the following result.

\section{PROPOSITION 4:}

(a) The RPC contract, $\mathrm{S}$, contains only two actual payments, $S_{\mathrm{G}}=M_{\mathrm{G}}$ and $S_{\mathrm{B}}=M_{\mathrm{B}}$, and a penalty, $\mathrm{P}(\mathrm{B})$, paid when the audited report is $\mathrm{B}$ and the agent communicated $\hat{\mathrm{G}}$, as follows:

$$
\mathrm{P}(\mathrm{B}) \leq \mathrm{W}^{-1}\left(\frac{\mathrm{W}\left(M_{B}\right)-(1-ð) \mathrm{W}\left(M_{G}\right)}{\partial}\right) .
$$

(b) Truth-telling is costless.

The proof is a summary of the above discussion. In particular, since (IC) are not binding, the asymmetry of information between principal and agent is costless and the principal's program collapses to that under MOC.

While the revelation contract yields the same payoffs as MOC, it is a different mechanism. In MOC, the audited report is redundant. In the revelation contract, it is vital for the success of the mechanism, because it is used to penalize an agent who falsely communicates $\mathrm{G}$ instead of B in order to deter misrepresentation by the agent.

We next characterize the contract when the agent has limited liability. The following lemma will ease the characterization. 


\section{LEMMA 3:}

When the agent communicates a bad outcome, he is paid a fixed amount that is independent of the audited report and the public signal; i.e., $S(\hat{x}=\hat{\mathrm{B}}, x=\mathrm{B})=S_{\hat{\mathrm{B}}}$.

Proof: See Appendix.

This lemma indicates that RPC includes at most four elements: three actual payments, $S_{\hat{\mathrm{G}} h}, S_{\hat{\mathrm{G}} \ell}$, and $S_{\hat{\mathrm{B}}}$, and a penalty, $\mathrm{P}(\hat{\mathrm{B}})$.

A critical feature of the unlimited-liability contract is that the agent is threatened by a penalty, $\mathrm{P}(\hat{\mathrm{B}})$, to deter him from deviating from the equilibrium path when he observes $\mathrm{B}$. When the agent is protected by limited liability, no payment in the contract can specify an amount lower than the limited liability. The agent's limited liability thus may render RPC as characterized in Proposition 4 infeasible.

In what follows, without loss of generality, we assume that $\mathrm{P}(\hat{\mathrm{B}})=\mathrm{L}$. The motivation for this assumption is to avoid multiplicity of equilibria because of off-equilibrium moves. By the consistency criterion of the sequential equilibrium (see Osborne and Rubinstein (1994)), a strategy profile must be a best response to the limit of beliefs that are consistent with this profile. Since the auditor verifies a truthful preliminary report with probability one, in the limit both the agent and the principal believe that a penalty would not be exercised if the agent reported honestly to the auditor. Thus, any effective penalty that (a) deters the agent from misrepresenting a bad outcome to the auditor (i.e., satisfying (R.B)) and (b) (weakly) exceeds the limited liability (i.e., satisfying (LL)) is an equilibrium! When $\mathrm{L}$ is sufficiently low, any payment between $\mathrm{L}$ and $\mathrm{P}\left(\mathrm{O}^{\mathrm{B}}\right)$ in Proposition 4 satisfies these two requirements. Without loss of generality, we choose the lowest possible payment as a penalty - the limited-liability level. 
Limited liability can affect RPC in three ways:

(a) The limited liability, L, may be sufficiently low for a penalty contract that pays the agent as in MOC to still be feasible: $\mathrm{L} \leq \mathrm{P}(\hat{\mathrm{B}})$ as characterized in Proposition 4.

(b) MOC is not feasible, but in equilibrium, the limited liability, L, does not affect the agent's expected utility.

(c) The limited liability, L, is sufficiently high that the agent's expected utility exceeds his reservation utility.

\section{PROPOSITION 5:}

Under the equilibrium limited-liability contract there are two critical levels of limitedliability payments, $\mathrm{L}^{\mathrm{R} *}, \mathrm{~L}^{\mathrm{R} * *}, \mathrm{~L}^{\mathrm{R} *}<\mathrm{L}^{\mathrm{R} * *}$, such that:

Case (a): When $\mathrm{L}<\mathrm{L}^{\mathrm{R} *}=\mathrm{L}^{\mathrm{C}_{*}}$, the principal designs a penalty contract as described in Proposition 4, with $\mathrm{P}(\hat{\mathrm{B}})=\mathrm{L}$.

Case (b): When $\mathrm{L}^{\mathrm{R} *} \leq \mathrm{L}<\mathrm{L}^{\mathrm{R} * *}=\mathrm{L}^{\mathrm{C} * *}$, the contract, $\left\{S_{\hat{\mathrm{G} h}}, S_{\hat{\mathrm{G}} \ell}, S_{\hat{\mathrm{B}}}, \mathrm{P}(\hat{\mathrm{B}})\right\}$, is similar to case (b) in the limited-liability NCC,

$$
S_{\hat{\mathrm{G}} h}=C_{G h} ; S_{\hat{\mathrm{G}} \ell}=\mathrm{C}_{\mathrm{G} \ell} ; \quad S_{\hat{\mathrm{B}}}=U o+\mathrm{V}\left(a_{2}\right)-\theta_{2} v .
$$

The agent obtains his reservation utility, Wo.

Case (c): When $\mathrm{L} \geq \mathrm{L}^{\mathrm{R} * *}$, the contract, $\left\{S_{\hat{\mathrm{G}} h}, S_{\hat{\mathrm{G}} \ell}, S_{\hat{\mathrm{B}}}, \mathrm{P}(\hat{\mathrm{B}})\right\}$ is similar to case (c) in the limited-liability NCC,

$$
\left.S_{\hat{\mathrm{G}} h}=C_{G h}=\mathrm{W}^{-1}\left(\mathrm{~W}(\mathrm{~L})+\frac{\mathrm{v}}{Q}\right)\right) ; S_{\hat{\mathrm{G}} \ell}=C_{\hat{\mathrm{G}} \ell}=\mathrm{L} ; S_{\hat{\mathrm{B}}}=\mathrm{W}^{-1}\left(\mathrm{~W}(\mathrm{~L})+(1-\pi)(1-\rho) \frac{v}{Q}\right) .
$$

The agent obtains the same expected utility as in case (c) of the limited-liability NCC,

$$
\mathrm{W}(\mathrm{L})+\left[\theta_{2} \rho+(1-\pi)\left(1-\theta_{2}\right)(1-\rho)\right] \frac{\mathrm{v}}{Q}=\mathrm{W}(\mathrm{L})+\operatorname{Pr}(r=\mathrm{G}, s=h \mid \mathrm{NCC}) \frac{\mathrm{v}}{Q}>\text { Wo. }
$$


Proof: See Appendix.

The main feature of RPC is a penalty designed to ensure that the agent's communication is truthful. The penalty is triggered by an audited report that indicates a worse outcome than the one reported by the agent. Interestingly, $\mathrm{L}^{\mathrm{C}} *$ and $\mathrm{L}^{\mathrm{C}} * *$ of $\mathrm{NCC}$ divide the range of possible limitedliability levels in RPC as well. When limited liability falls below $\mathrm{L}^{\mathrm{C}}$, $\mathrm{RPC}$ coincides with MOC (case (a)). The intuition of this result is that, since the principal elicits the superior information of the agent about outcome, RPC and MOC are informationally equivalent. RPC, however, requires the principal to induce the agent to send a truthful message. The agent is eager to reveal a good outcome, because, to induce him to exert effort, he is paid more than when the outcome is bad. When the outcome is bad, the threat of a penalty, triggered by a pending audit's discovery of the truth, deters the agent from misrepresenting. Since limited liability is low, the principal can set the penalty at a level sufficiently high to not need to pay for the elicitation of the agent's private information. ${ }^{16}$

When limited liability exceeds $\mathrm{L}^{\mathrm{C} *}, \mathrm{RPC}$ resembles NCC (cases (b) and (c)). When the outcome is good, the agent's payment schedule is identical under both contracts. When the outcome is bad, the agent is paid a fixed salary, and the principal enjoys the reduced cost due to replacing a gamble (in NCC) with a fixed payment to the risk-averse agent (in RPC). As before, when limited liability exceeds (falls below) $\mathrm{L}^{\mathrm{C}_{* *}}$, the agent does (does not) enjoy a rent. We find this result perplexing in light of the fact that NCC and RPC are different regarding the principal's knowledge of outcome. The similarity is due to the fact that limited liability prevents the principal from using his ability to elicit the truth from the agent to reduce the information rent of

\footnotetext{
${ }^{16}$ As the numerical examples below show, a penalty payment does not necessarily involve a payment from the agent to the principal. When the penalty is a transfer from the principal, then, the sentence should read: "Since limited liability is low, the principal can set the transfer at a level sufficiently lowto not need to pay for the elicitation of the agent's private information."
} 
the privately-informed agent (who alone observes outcome). The principal does enjoy a cheaper contract, but only because there is opportunity for better risk-sharing.

The differences between RPC and NCC lend the following insight.

\section{PROPOSITION 6:}

The contracts of Proposition 5 are Pareto superior to NCC.

The proof is evident from the facts that: (i) the agent obtains the same expected utility under NCC and RPC, and (ii) the principal effects improved risk-sharing when $x=\mathrm{B}$ and hence pays less to the risk-averse agent.

We conclude with some numerical examples.

Insert Exhibit 1 about here.

\section{SUMMARY}

In many principalagent relationships, the principal must design a contract that takes into account the agent's limited liability. Since this issue is largely ignored in the analytical research, the question is whether ignoring it entails loss of generality. We characterize the principal-agent contract for the whole spectrum of possible limited-liability levels (from minus infinity to an arbitrary high level) when the agent can engage in "report management," because he alone observes actual outcome, and when the principal receives an imperfectly audited report by a third party, an auditor.

As a benchmark case, we analyze the contract when the principal observes the actual outcome (MOC). We find that in terms of the agent's utility limited liability shifts all components 
of the contracts upwards. If limited liability affects the contract, the agent enjoys a rent beyond his reservation utility. The harder it is to motivate the agent to exert effort, the more costly limited liability is to the principal.

We then analyze a setting where the principal does not observe outcome. He can base the contract, instead, on an imperfectly audited report of outcome. We distinguish between two cases. In the first, communication channels are blocked. Hence, the agent attempts to manage the report. In the second, the principal and agent can communicate again before the auditor's report (and after the agent has learned the actual outcome). To solve for the contract, we invoke the revelation principle, which states that designing a truthful, direct mechanism entails no loss of generality.

The main findings are that, when outcome is not observed by the principal, (1) only when limited liability does not exceed a critical maximum threshold, the cost to the less-informed principal of earnings management can be completely avoided through the design of a contract that invokes the revelation principle. That is, the payoffs of a revelation contract coincide with the payoffs of a contract based on a mutually observable outcome, provided limited liability is low. [See the first line in Exhibit 1.] The only difference between the two contracts is that the former uses the audited report of outcome following the agent's communication as a threat to induce truth-telling report. (2) When limited liability exceeds this critical maximum threshold, the structure of the revelation contract changes, and now resembles that of a contract with blocked communication. Specifically, both contracts will include a post-outcome imperfect public signal as an argument in the compensation function. The principal fine-tunes payments based on the post-outcome signal to compensate for the loss in flexibility caused by the agent's limited liability. For some limited-liability levels, the principal thus pushes the agent closer to his reservation utility level. [See footnote 12.] 


\section{References}

Antler, R. and G.D. Open. 1985. Capital rationing and organizational slack in capital budgeting. Management Science 31(2): 163-174.

Arya, A., J. Glover, and K. Sivaramakrishnan. 1997. The interaction between Decision and Control Problems and the Value of Information. The Accounting Review 72(4): 561-574.

Arya, A., J. Glover, and S. Sunder. 1998. Earnings management and the Revelation Principle. Review of Accounting Studies 3: 7-34.

Baiman, S., and J.S. Demski. 1980a. Economically optimal performance evaluation and control systems. Journal of Accounting Research (supplement) 18: 184-220.

------, and J.S. Demski. 1980b. Variance analysis procedures as motivational devices. Management Science 26(8):840-848.

------, and J.H. Evans III. 1983. Pre-decision information and participative management control systems. Journal of Accounting Research 2: 371-395.

------, J.H. Evans, and J. Noel. 1987. Optimal contracts with a utility-maximizing auditor. Journal of Accounting Research 25: 217-244.

------, and M.V. Rajan. 1998. Optimal cost targets and incentives for acquiring expertise, Review of Accounting Studies 3(3):231-259.

Baliga S., and T. Sjöström. 1998. Decentralization and collusion. Journal of Economic Theory 83: 196-232.

Basu, K. 1992. Limited liability and the existence of share tenancy. Journal of Development Economics 47: 203-220.

Border, K.C., and J. Sobel. 1987. Samurai accountant: A theory of auditing and plunder. Review of Economics Studies 54(4): 525-540.

Christensen, P.O., and J. Feltham. 1997. Sequential communication in agencies, Review of Accounting Studies 2(2): 123-155.

--------. 1999. Market based performance measures and disclosure of private information in capital Markets, Review of Accounting studies. Forthcoming.

Dechow, P.M. and D.J. Skinner. 2000. Earnings management; reconciling the vie ws of accounting academics, practitioners, and regulators. Accounting Horizons 14(2): 235-250.

Demougin, D.M. and D.A. Garvie. 1991. Contractual design with correlated information under limited liability. Rand Journal of Economics 22: 477-489. 
Demski, J.S. 1998. Endogenous measure manipulation Contemporary Accounting Research 15(3):261-285.

Demski, J.S., and D.E.M. Sappington. 1984. Optimal incentive contract with multiple agents. Journal of Economic Theory 33: 152-171.

-----, 1993. Sourcing with unverifiable performance information. Journal of Accounting Research 31: 1-20.

-------, and P. Spiller, 1988. Incentive schemes with multiple agents and bankruptcy, Journal of Economic Theory 44: 156-167.

Evans, J.H. 1980. Optimal contract with costly conditional auditing. Journal of Accounting Research 18(supp):108-128.

------, and S.S. Sridhar. 1996. Multiple control systems, accrual Accounting, and earning management. Journal of Accounting Research 34: 45-65.

Gale, D. and M. Hellwig. 1985. Incentive-compatible debt contracts: The one-period problem. Review of Economic Studies 52: 647-663.

Harris, M., and A. Raviv. 1979. Optimal incentive contracts with imperfect information. Journal of Economic Theory 20: 231-259.

Healy, P.M. 1985. The effect of bonus schemes on accounting decisions. Journal of Accounting and Economics 7: 85-107.

------, and J.M. Wahlen. 1999. A review of the earnings management literature and its implications for standard setting. Accounting Horizons 13: 365-384.

Holmstrom, B. 1979. Moral hazard and observability. Bell Journal of Economics 10: 74-91.

Kim, S.K. 1997. Limited liability and bonus contracts. Journal of Economics and Management Strategy 6: 899-913.

Kanodia, C. 1985. Stochastic monitoring and moral hazard. Journal of Accounting Research23: 175-193.

Kim S.K. and Y.S. Suh. 1991. Ranking of accounting information systems for management control. Journal of Accounting Research 29:386-396.

Innes, R.D. 1990. Limited liability and incentives contracting with ex-ante action choices. Journal of Economic Theory 52: 45-67. 
Lawarrée, J.P. and M.A. Van Audenrode. 1992. Cost observation, auditing and limited liability. Economic Letters 39: 419-423.

------ 1996. Optimal contract, imperfect output observation, and limited liability, Journal of Economic Theory 71: 514-531.

Levitt, C.A. 1998. The "Numbers game." A speech delivered at the NYU Center for Law and Business, New York, N.Y. Available on http://www.sec.gov.news.speeches/spch220.txt.

Ma. C.A. 1991. Adverse selection in dynamic model. Quarterly Journal of Economics 106: 255-275.

Mehta, R.A. 1993. A solution to a class of agency problems, with application to the question of Limited liability, Economic Letters 43: 193-197.

Mirrlees, J. 1974. Notes of welfare economics, information and uncertainty. Balch, Ncfadden, and Wu, eds. In Essays in Economic Behavior Under Uncertainty. Amsterdam. NorthHolland Publishing Co.

Newman, P. 1998. Discussion of "Performance Measure Manipulation." Contemporary Accounting Research 15(3): 287-290.

Osborne, M. and A. Rubinstein, 1994. A Course in Game Theory. The MIT Press: Cambridge, Massachusetts; London, England.

Park, E-S. 1995. Incentive contracting under limited liability. Journal of Economics and Management Strategy 4(4): 477-490.

Pitchford, R. 1998. Moral hazard and limited liability: The real effects of contract bargaining, Economics Letters 61: 251-259.

Ronen, J. and S. Sadan. 1981. Smoothing income numbers: objectives, means, and implications Eddison Wesley Publishing Company.

Sappington, D. 1983. Limited liability contracts between principal and agent. Journal of Economics Theory 29: 1-21.

Schwartz, R. 1997. Legal regimes, audit quality and investment. The Accounting Review 72: 385406.

Sengupta, K. 1997. Limited liability, moral hazard and share tenancy. Journal of Development Economics 52: 393-407.

Townsend, R.M. 1979. Optimal contract and competitive markets with costly state verification. Journal of Economic Theory 21(2): 265-293. 
Tzur, J. and V.L. Yaari. 1999. Microstructure of firm's disclosure Review of Quantitative Finance and Accounting 13: 367-391. 


\section{APPENDIX}

\section{Proof of Proposition 1:}

\section{$\underline{\text { Part a: }}$}

By Lemma 1, when limited liability is not effective, the bad-outcome payment, in utils, equals $\mathrm{W}_{\mathrm{o}}+\mathrm{V}\left(a_{2}\right)-\theta_{2} v$, while the good-outcome payment equals $\mathrm{W}_{\mathrm{o}}+\mathrm{V}\left(a_{2}\right)+\left(1-\theta_{2}\right) v$. The fact that limited liability matters implies that $\mathrm{W}_{\mathrm{o}}+\mathrm{V}\left(a_{2}\right)-\theta_{2} v$ is lower than $\mathrm{W}(\mathrm{L})$. The expected utility of the agent, then, is

$\theta_{2}[\mathrm{~W}(\mathrm{~L})+v]+\left(1-\theta_{2}\right) \mathrm{W}(\mathrm{L})-\mathrm{V}\left(a_{2}\right)>\theta_{2}\left[\mathrm{~W}_{\mathrm{o}}+\mathrm{V}\left(a_{2}\right)+\left(1-\theta_{2}\right) v\right]+\left(1-\theta_{2}\right)\left[\mathrm{W}_{\mathrm{o}}+\mathrm{V}\left(a_{2}\right)-\theta_{2} v\right]=\mathrm{Wo}$

\section{$\underline{\text { Part b: }}$}

$$
\Delta \equiv \theta_{2} \mathrm{~W}^{-1}[\mathrm{~W}(\mathrm{~L})+v]+\left(1-\theta_{2}\right) \mathrm{L}-\left\{\theta_{2} \mathrm{~W}^{-1}\left[\mathrm{~W}_{\mathrm{o}}+\mathrm{V}\left(a_{2}\right)+\left(1-\theta_{2}\right) v\right]+\left(1-\theta_{2}\right) \mathrm{W}^{-1}\left[\mathrm{~W}_{\mathrm{o}}+\mathrm{V}\left(a_{2}\right)-\theta_{2} v\right]\right\}
$$

Taking a derivative with respect to $v$ yields

$$
\theta_{2}\left[\frac{1}{\left.\mathrm{~W}^{\prime}(\mathrm{W}(\mathrm{L})+v)\right)}-\frac{1-\theta_{2}}{\mathrm{~W}^{\prime}\left(\mathrm{Wo}+\mathrm{V}\left(a_{2}\right)+\left(1-\theta_{2}\right) v\right)}\right]+\frac{\left(1-\theta_{2}\right) \theta_{2}}{\mathrm{~W}^{\prime}\left(\mathrm{Wo}+\mathrm{V}\left(a_{2}\right)-\theta_{2} v\right)}>0
$$

This expression is positive because, by the concavity of the agent's utility function, his marginal utility is a decreasing function; hence, since $\mathrm{W}(\mathrm{L})>\mathrm{Wo}+\mathrm{V}\left(a_{2}\right)-\theta_{2} v$, the first argument is positive. Q.E.D.

\section{Proof of Lemma 2:}

Part (a) follows from the $(\mathrm{MH})$ constraint. To induce the agent to exert effort, he must be paid more for $x=\mathrm{G}$ than for $x=\mathrm{B}$, which establishes part (b), because such an incentive scheme induces the agent to misrepresent a bad outcome. Q.E.D. 


\section{Proof of Proposition 2:}

Part a:

We prove that $C_{G \ell}>C_{\mathrm{B}}$. The proof that $C_{\mathrm{Gh}}>C_{G \ell}$ is similar. $C_{G \ell}>C_{\mathrm{B}}$ if

$$
\frac{\grave{1}(\text { ð }-Q)}{\operatorname{Pr}(r=G, s=\ell)}+\frac{\grave{\imath} \text { ð }}{\operatorname{Pr}(r=\mathrm{B})}>0 .
$$

This inequality obtains if

$$
\mu[1-\rho-(1-\pi) \rho]\left[\pi\left(1-\theta_{2}\right)\right]+\mu \tau\left[\theta_{2}(1-\rho)+(1-\pi)\left(1-\theta_{2}\right) \rho\right]>0 .
$$

Upon rearranging, we obtain $(1-\rho)\left[\left(1-\theta_{2}\right)+\theta_{2}\right]=1-\rho>0$, so the proof is established.

\section{$\underline{\text { Part b: }}$}

The proof is immediate, because while NCC is feasible it is different from the solution to a program with an observable outcome (MOC). Q.E.D.

\section{Proof of Proposition 3:}

First, we establish that the contract varies with $\mathrm{L}$ according to the two critical levels, $\mathrm{L}^{\mathrm{C}^{*}}$ and $\mathrm{L}^{\mathrm{C} * *}$. This follows from the transitive ordering of the contract's payments when the limitedliability constraints are not binding. To illustrate, if (LL) were binding, say, for $C_{\mathrm{Gh}}$, then it would certainly be binding for the rest of the payments, because if not we obtain, by contradiction, that lower payments were not constrained by the agent's limited liability, L. Note that this hypothetical scenario cannot take place because it implies a flat wage contract, $\mathrm{L}$ that violates the agent's incentives to exert effort.

The proof of (a) replicates the proof of Proposition 2. Note that, unlike MOC, we cannot characterize NCC in closed form unless one (LL) constraint is binding (cases (b) and (c)), because the contract is comprised of three variables, while our constraints, $(\mathrm{PC})$ and $(\mathrm{MH})$, provide only 
two equations. Case (b) is solved by substituting $\mathrm{C}_{\mathrm{B}}=\mathrm{L}$ into (PC) and (MH) and solving for two variables only, $C_{\mathrm{Gh}}$ and $C_{G \ell}$. Case (c) is solved by substituting $\mathrm{C}_{\mathrm{B}}=\mathrm{L}$ and $C_{G \ell}=\mathrm{L}$ into (MH). The proof that (PC) is binding, i.e., that the agent's expected utility is Wo, in case (b) and non-binding in case (c) is as follows. In both cases, by (MH),

$$
\mathrm{W}\left(C_{\mathrm{Gh}}\right)=\frac{v}{Q}-\frac{\partial-Q}{Q} \mathrm{~W}\left(C_{G \ell}\right)+\frac{\partial}{Q} \mathrm{~W}\left(C_{B}\right) .
$$

That is, $C_{\mathrm{Gh}}$ increases in $\mathrm{C}_{\mathrm{B}}$ and decreases in $C_{G \ell}$. Therefore, when limited liability forces the principal to increase $\mathrm{C}_{\mathrm{B}}$, the principal can still design a contract that provides the agent with incentives to exert effort for a price that equals Wo in the agent's utils, by reducing $C_{G \ell}$; i.e., $\partial C_{G \ell} / \partial \mathrm{L}<0 . \quad$ Substituting $C_{\mathrm{Gh}}$ in $(\mathrm{PC})$, we obtain

$$
\beta \mathrm{W}\left(C_{G \ell}\right)+\beta^{\prime} \mathrm{W}(\mathrm{L})-k \geq \mathrm{Wo}
$$

where

$$
\begin{aligned}
& \beta=\operatorname{Pr}(r=\mathrm{G}, s=\ell)-\operatorname{Pr}(r=\mathrm{G}, s=h) \frac{\partial-Q}{Q} . \\
& \beta^{\prime}=ð\left(1-\theta_{2}\right)+\operatorname{Pr}(r=\mathrm{G}, s=h) \frac{\partial}{Q} . \\
& k=\mathrm{V}\left(a_{2}\right)-\operatorname{Pr}(r=\mathrm{G}, s=h) \frac{v}{Q} .
\end{aligned}
$$

In case (b), $\mathrm{C}_{G \ell}>\mathrm{L}$ (because the (LL) constraint is not binding for this payment). Hence, the principal can reduce $\mathrm{C}_{G \ell}$ until (PC) binds. In case (c) he does not have this flexibility, and the (LL) constraints dictate a higher $\mathrm{C}_{G \ell}$, implying a nonbinding (PC).

Finally, the result that the limited-liability constraints cause an increase in the contract's cost is trivial. Q.E.D. 


\section{Proof of Lemma 3:}

Suppose not. The contract then is based on the public signal and the agent's communication (the audit report is redundant, because it confirms that the agent communicates the truth). In this case, the agent is paid $S_{\hat{\mathrm{B}} h}$ when the public signal is high and $S_{\hat{\mathrm{B}} \ell}$ when demand is low. The Lagrangian of the S-program, N, given that (IC.G) is not binding, is

$$
\left.\left.\mathrm{N}=\left[(1-\rho)\left(-1+\mathrm{N}_{1}\right)+\varphi^{\hat{\mathrm{B}} h}\right] \mathrm{W}\left(S_{\hat{\mathrm{B}} h}\right)\right]+\left[\rho\left(-1+\mathrm{N}_{1}\right)+\varphi^{\hat{\mathrm{B}} \ell}\right] \mathrm{W}\left(S_{\hat{\mathrm{B}} \ell}\right)\right]+\mathrm{N}_{2},
$$

where $\mathrm{N}_{1}=\lambda \pi\left(1-\theta_{2}\right)-\mu \pi+\eta+\varphi^{\hat{\mathrm{B}} h} ; \eta$ is the Lagrange multiplier of (IC.B); and $\mathrm{N}_{2}$ is all the arguments in the Lagrangian that arise from the principal and the agent sharing the good outcome.

The thrust of the proof is to show that $S_{\hat{\mathrm{B}} h}=S_{\hat{\mathrm{B}} \ell}$.

Case (1): If neither $\varphi^{\hat{\mathrm{B}} h}$ nor $\varphi^{\hat{\mathrm{B}} \ell}$ is binding, the first-order-conditions after rearranging are the same, so $S_{\hat{\mathrm{B}} h}=S_{\hat{\mathrm{B}} \ell}$.

Case (2): If both $\varphi^{\hat{\mathrm{B}} h}$ and $\varphi^{\hat{\mathrm{B}} \ell}$ are binding, then $S_{\hat{\mathrm{B}} h}=S_{\hat{\mathrm{B}} \ell}=\mathrm{L}$.

Case (3): If only $\varphi^{\hat{\mathrm{B} h}}$ is binding, then the first-order-conditions are

$$
\begin{aligned}
& \frac{1}{\mathrm{~W}^{\prime}\left(S_{\hat{\mathrm{B}} h}\right)}=\lambda-\frac{(1-\rho) \mu \pi}{(1-\rho) \pi\left(1-\theta_{2}\right)}+\frac{\varphi^{\hat{\mathrm{B}} h}}{\operatorname{Pr}(x=\mathrm{B}, w=h)}=\lambda-\frac{\mu}{1-\theta_{2}}+\frac{\varphi^{\hat{\mathrm{B}} h}}{\operatorname{Pr}(x=\mathrm{B}, w=h)} . \\
& \frac{1}{\mathrm{~W}^{\prime}\left(S_{\hat{\mathrm{B}} \ell}\right)}=\lambda-\frac{\rho \mu \pi}{\rho \pi\left(1-\theta_{2}\right)}=\lambda-\frac{\mu}{1-\theta_{2}} .
\end{aligned}
$$

Clearly, if $\ddot{e}-\frac{\grave{1}}{1-\grave{e}_{2}}$ is so low to invoke the limited-liability constraint when public signal is high, then $\varphi^{\hat{\mathrm{B}} \ell}$ must be positive too, and we are back to case (2). 
Case (4): If only $\varphi^{\hat{\mathrm{B}} \ell}$ is binding, we obtain the same contradiction as in (3). Q.E.D.

\section{Proof of Proposition 5:}

Case (a) occurs when L is sufficiently low to make feasible the MOC's payoff in the limited-liability RPC; i.e., (R.B) is not binding.

Case (b) occurs when (R.B) is binding. In this case,

$$
\begin{aligned}
& \theta_{2}\left[\rho \mathrm{W}\left(S_{\hat{\mathrm{G}} h}\right)+(1-\rho) \mathrm{W}\left(S_{\hat{\mathrm{G}} \ell}\right)\right]+\left(1-\theta_{2}\right) \mathrm{W}\left(S_{\hat{\mathrm{B}}}\right)-\mathrm{V}\left(a_{2}\right)=\mathrm{Wo} \quad(\mathrm{PC}) \\
& Q \mathrm{~W}\left(S_{\hat{\mathrm{G}} h}\right)+(\pi-Q) \mathrm{W}\left(S_{\hat{\mathrm{G}} \ell}\right)-\mathrm{W}\left(S_{\hat{\mathrm{B}}}\right)=v
\end{aligned}
$$

Upon multiplication of (MH) by $\theta_{2}$, we find that

$$
\theta_{2}\left[\pi \mathrm{W}\left(S_{\hat{\mathrm{G}} h}\right)+(1-\pi) \mathrm{W}\left(S_{\hat{\mathrm{G}} \ell}\right)\right]=v+\theta_{2} \mathrm{~W}\left(S_{\hat{\mathrm{B}}}\right) .
$$

Substituting in (PC) and rearranging yield the desired expression for $S_{\hat{\mathrm{B}}}$. Substituting (R.B) in the (PC) and (MH) reveals that they become the same equations as in NCC case (b) with two unknowns, $S_{\hat{\mathrm{G}} h}$ and $S_{\hat{\mathrm{G}} \ell}$.

The proof of $\mathrm{L}^{\mathrm{R} *}=\mathrm{L}^{\mathrm{C} *}$ is based on the characterization of the contract, the binding (PC) in both programs, and the binding (R.B). ${ }^{17}$

\footnotetext{
${ }^{17}$ In NCC, the binding (PC) is

$\operatorname{Pr}(r=\mathrm{G}, s=h) \mathrm{W}\left(C_{\mathrm{G} h} \mid \mathrm{L}^{\mathrm{C}_{*}}\right)+\operatorname{Pr}(r=\mathrm{G}, s=\ell) \mathrm{W}\left(C_{G} \mid \mathrm{L}^{\mathrm{C}_{*}}\right)+\pi\left(1-\theta_{2}\right) \operatorname{Pr}(x=\mathrm{B}) \mathrm{W}\left(\mathrm{L}^{\mathrm{C}_{*}}\right)-\mathrm{V}\left(a_{2}\right)=\mathrm{Wo}$.

In RPC, (PC) is $\theta_{2}\left[\rho \mathrm{W}\left(S_{\hat{\mathrm{G}} h}\right)+(1-\rho) \mathrm{W}\left(S_{\hat{\mathrm{G}} \ell}\right)\right]+\left(1-\theta_{2}\right) \mathrm{W}\left(S_{\hat{\mathrm{B}}}\right)-\mathrm{V}\left(a_{2}\right)=\mathrm{Wo}$.

Substituting the binding (R.B) in the (PC) of the RPC contract's program, (PC) becomes $\left[\theta_{2} \rho+(1-\pi)\left(1-\theta_{2}\right)(1-\rho)\right] \mathrm{W}\left(S_{\hat{\mathrm{G}} h}\right)+\left[\theta_{2}(1-\rho)+(1-\pi)\left(1-\theta_{2}\right) \rho\right] \mathrm{W}\left(S_{\hat{\mathrm{G}} \ell}\right)+\pi\left(1-\theta_{2}\right) \mathrm{W}\left(\mathrm{L}^{\mathrm{C}} *\right)-\mathrm{V}\left(a_{2}\right)=\mathrm{Wo}$
} 
Case (c) occurs when (R.B) is binding and $S_{\hat{\mathrm{G}} \ell}=\mathrm{L}$. It is immediate to verify that this parallels case (c) in limited-liability NCC.

The proof of $\mathrm{L}^{\mathrm{R} * *}=\mathrm{L}^{\mathrm{C} * *}$ is based on the characterization of the RPC and the NCC contracts, the binding $(\mathrm{MH})$ in both programs, and the binding (R.B), in a fashion similar to the proof that $\mathrm{L}^{\mathrm{R} *}=\mathrm{L}^{\mathrm{C} *}$ in case (b). Q.E.D. $\pi)\left(1-\theta_{2}\right) \rho$, and (b) the agent's payment is the same under both contracts when the firm reports a good outcome, it is straightforward to see that (PC) holds in both programs only if $\mathrm{L}^{\mathrm{R} *}=\mathrm{L}^{\mathrm{C}} *$. 


\section{EXHIBIT 1: NUMERICAL EXAMPLES*}

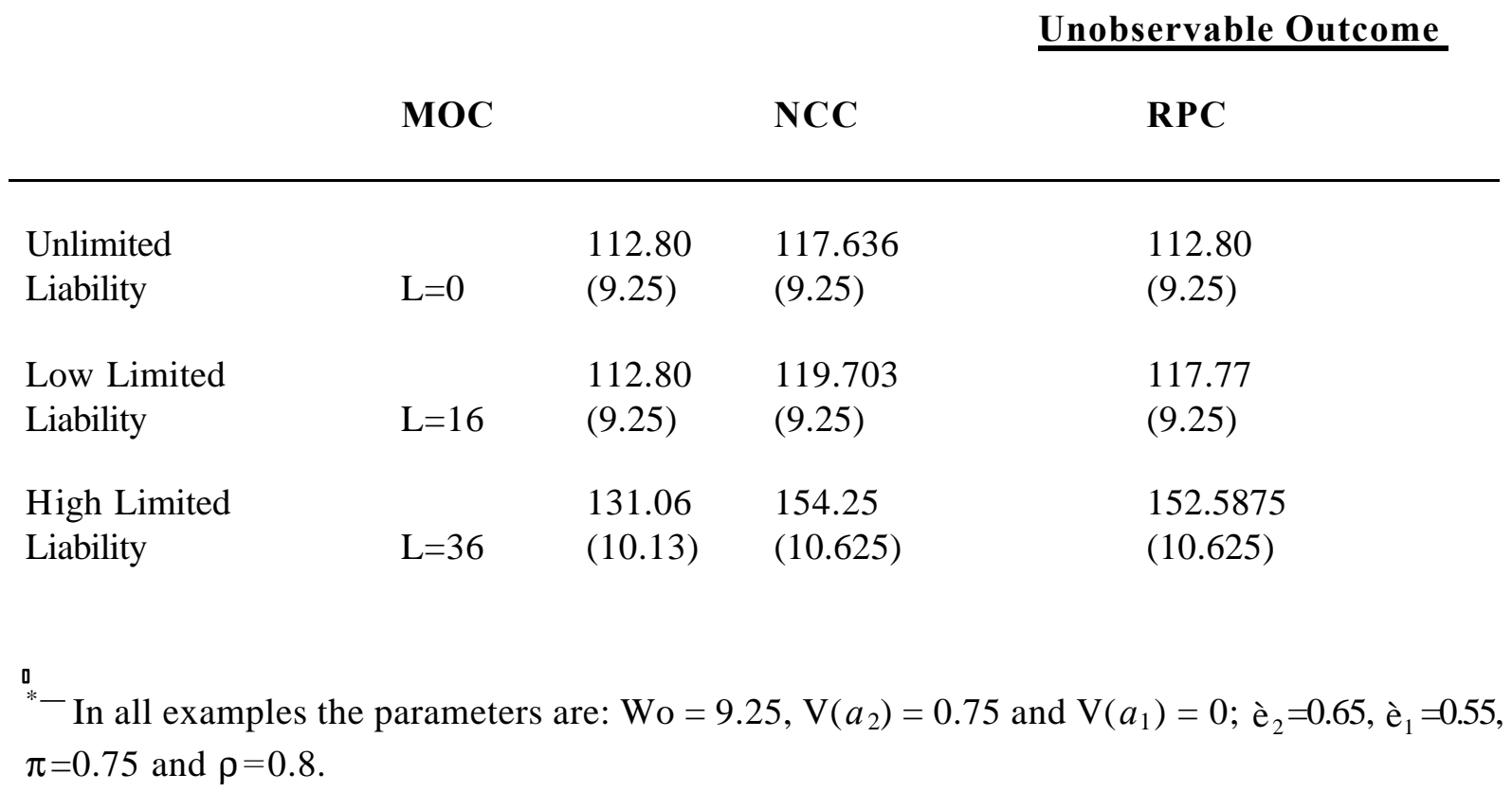

